\title{
Welfare effects of unbundling under different regulatory regimes in natural gas markets
}

\author{
António Brandão ${ }^{1} \cdot$ Joana Pinho $^{1} \cdot$ Joana Resende $^{1}$. \\ Paula Sarmento $^{1} \cdot$ Isabel Soares $^{1}$
}

Received: 30 September 2013 / Accepted: 10 February 2016 / Published online: 26 February 2016 (C) ISEG 2016

\begin{abstract}
In this paper, we develop a theoretical model that enriches the literature on the pros and cons of ownership unbundling vis-à-vis lighter unbundling frameworks in the natural gas markets. For each regulatory framework, we compute equilibrium outcomes when an incumbent firm and a new entrant compete $a$ la Cournot in the final gas market. We find that the entrant's contracting conditions in the upstream market and the transmission tariff are key determinants of the market structure in the downstream gas market (both with ownership and with legal unbundling). We also study how the regulator must optimally set transmission tariffs in each of the two unbundling regimes. We conclude that welfare maximizing tariffs often require free access to the transmission network (in both regulatoy regimes). However, when the regulator aims at promoting the break-even of the regulated transmission system operator, the first-best tariff is unfeasible in both regimes. Hence, we study a more realistic set-up, in which the regulator's action is constrained by the break-even of the regulated firm (the transmission system operator). In this set-up, we find that, for
\end{abstract}

Joana Resende

jresende@fep.up.pt

António Brandão

abrandao@fep.up.pt

Joana Pinho

jpinho@fep.up.pt

Paula Sarmento

sarmento@fep.up.pt

Isabel Soares

isoares@fep.up.pt

1 CEF.UP, University of Porto, Porto, Portugal 
a given transmission tariff, final prices in the downstream market are always higher with ownership unbundling than with legal unbundling.

Keywords Ownership unbundling ' Legal unbundling ' Access price regulation . Natural gas market · Transmission tariffs

JEL Classification L50 $\cdot$ L43 $\cdot$ L95 